\title{
Mobilidade do sujeito e dos sentidos no espaço político: processos de identificação/desidentificação
}

\author{
Maria do Socorro Aguiar de Oliveira Cavalcante ${ }^{1}$
}

\begin{abstract}
Résumé: Par la voi de l'Analyse du Discours, ancrée dans le Materialisme Historique Dialetique, ce travail a comme objectif analyser les diferentes positions du sujet assumés par l'ancien président Luiz Inácio Lula da Silva, dans des différents moments de sa trajetoire politique. Nous partons d'une vision de discours en tant que lieu d'action de sujets, une práxis humaine qui peut être comprise a partir de contraditions sociales qui expriment toujours des lieux discursifs qui comprennent des relacions sociales, historiques et ideologiques.
\end{abstract}

Mots-clés: sujet; discours; identification/desidentification.

Resumo: Pela via da Análise do Discurso, ancorada no Materialismo Histórico Dialético, este trabalho tem por objetivo analisar as diferentes posições de sujeito assumidas pelo ex-presidente Luiz Inácio Lula da Silva, em diferentes momentos de sua trajetória política. Partimos de uma visão de discurso como lugar de ação dos sujeitos, u ma práxis humana que não pode ser compreendida senão a partir do entendimento das contradições sociais que exprimem sempre lugares discursivos resultantes das relações sociais, históricas e ideológicas.

Palavras-chave: sujeito; discurso; identificação/desidentificação.

Introdução

Retomando o que já dissemos em Cavalcante et.all (2009), ${ }^{2}$ este artigo resulta "da tessitura de uma rede de muitos fios de vozes que se cruzam, dialogam, se completam, respondem umas as outras, e, ás vezes, até polemizam."

Iniciamos a construção desta "teia" com GREGOLIN (2003, p. 47) que diz: "há textos que nos parecem familiares, reclamando leituras. [...] A aparição de um texto só se completa quando um leitor o insere na ordem da história, deslocando-o do lugar onde jaz, reclamando sentidos." Foi esse sentimento de familiaridade que nos tocou quando nos deparamos com o artigo de Orlandi (2013) - Uma tautologia ou um embuste semântico-discursivo? Ainda a propaganda do Estado: País rico é país sem pobreza. Neste artigo, a autora analisa o enunciado, propaganda do governo Dilma - País rico é país sem pobreza.

A leitura do referido texto fez ecoar outros textos, também de propagandas com a mesma temática, surgidas em vários governos, iniciando por Fernando Henrique com

1 Docente dos Cursos de Graduação e de Pós-Graduação em Educação e Letras da Universidade Federal de Alagoas - UFAL

2 Cf. FLORENCIO et all - Análise do Discurso:procedimentos e prática. 
o programa Bolsa Escola e continuando nos governos Lula e Dilma com os programas Fome Zero, Bolsa Família, entre tantos outros. Este último, também pensado com o objetivo de combater a pobreza no Brasil, vinculado á escolarização de crianças e jovens. Nosso objetivo neste, artigo, no entanto, não é analisar o Programa Bolsa Família, mas discursos antagônicos produzidos a partir do acontecimento histórico que possibilitou seu surgimento, ou seja, a conjuntura histórico-ideológica que possibilitou o engendramento do acontecimento discursivo.

É a partir da análise dessas condições que poderemos chegar ao entendimento de como os sentidos do discurso se constituem e interferem na realidade, como transformação ou estabilização do sentido pretendido. Como já foi dito em Florencio et all (2009,p. 65), "para a $\mathrm{AD}$, não há sentido dado, único, verdadeiro, mas sentidos vários que estão além das evidências, porque são produzidos por sujeitos que realizam suas escolhas em determinadas situações e que se mostram no modo como dizem.”

Quando dizemos que os sujeitos fazem escolhas, não estamos nos referindo a um sujeito autônomo, soberano, que tudo pode, mas a um sujeito determinado por uma objetividade que o interroga, que o provoca a buscar respostas para questões atinentes à realidade concreta, com suas possibilidades e limites. pois nenhuma realidade oferece apenas uma alternativa. É diante das alternativas (por mais limitadas que sejam), postas pela realidade objetiva, que o sujeito faz escolhas e introduz as marcas das relações de classe de seu tempo. É o próprio Marx (2001) quem afirma que a cada tempo e espaço social cabe uma individualidade que reage ás determinações, a partir das possibilidades da própria objetividade. Reagindo a alternativas colocadas pela realidade objetiva, o sujeito o faz aceitando-as, delas discordando, modificando-as, retendo certos elementos nelas existentes. Segundo Magalhães et all (2009, p. 51), "é nesse espaço de escolhas que a subjetividade exerce a capacidade de produzir o novo em todas as práticas humanas, inclusive a discursiva". Segundo PECHEUX (1990, p. 56), "Todo discurso é o índice potencial de uma agitação nas filiações sócio-históricas de identificação, na medida em que ele constitui ao mesmo tempo um efeito dessas filiações e um trabalho (mais ou menos consciente, deliberado,[...] mas de todo modo, atravessado pelas determinações inconscientes) de deslocamento no seu espaço."

É possível perceber, nesse trecho, que, para Pêcheux a produção do discurso se dá, mediante um processo de identificação do sujeito com as filiações sócio-históricas, admitindo uma agitação no interior delas. Ou seja, o sujeito toma posição, identificando-se ou desidentificando-se com determinada filiação ideológica, lembrando sempre que esse deslocamento do sujeito só é possível, a partir do que a realidade objetiva lhe permite escolher. Nesse sentido, afirma MAGALHÃES et all (2007, p. 140),

O discurso não é uma construção independente das relações sociais, mas ao contrário, o fazer discursivo é uma práxis humana que só pode ser compreendida a partir do entendimento das contradições sociais que possibilitaram sua objetivação. Pêcheux enfatiza esse fato em todos os seus textos, ao submeter a formação discursiva ás formações ideológicas que, por sua vez expressam as contradições de classes antagônicas da sociedade.

É a partir desses pressupostos que nos propomos analisar as diferentes posições de sujeito assumidas pelo ex-presidente da república Luiz Inácio Lula da Silva, sobre o mesmo acontecimento - Bolsa família - em diferentes momentos de sua trajetória - como líder do sindicato de metalúrgicos e como presidente da república - verificando como essas posições ideologicamente atravessadas, interferem nos processos de identificação/desidentificação que se corporificam e se revelam em discursos, materializados pela linguagem. 
Bolsa Família: "uma peça de troca"

A materialidade apresentada a seguir foi transcrita de um vídeo intitulado Lula contra Lula ${ }^{3}$ que contém depoimentos do ex-presidente, antes e depois de assumir o poder. Vejamos Lula em 2000, posicionando-se sobre os programas sociais de seu oponente, eleito Presidente da República

Lamentavelmente, no Brasil, o voto não é ideológico.. Lamentavelmente, no Brasil, as pessoas não votam partidariamente.

Lamentavelmente, no Brasil, você tem uma parte da sociedade, que pelo alto grau de empobrecimento, é conduzida a pensar pelo estômago e não pela cabeça. É por isso que se distribui tanta cesta básica, tanto ticket de leite, porque isso na verdade é uma peça de troca no momento da eleição e assim se despolitiza o processo eleitoral. Assim, você trata o povo mais pobre no Brasil, da mesma forma que Cabral tratou os indios, distribuindo bugigangas para ganhar os índios, você distribui alimentos. Você tem como lógica manter a política de dominação que é secular no Brasil (Grifos nossos)

De que lugar (discursivo) fala Lula e a partir de que posição de classe, considerando que a tomada de posição do sujeito revela sempre sua posição de classe? Com que Formação Ideológica esse sujeito se identifica?

Segundo LEONTIEV, (2004, pp.104,105), "todo sentido é sentido de alguma coisa. Com efeito, o sentido traduz precisamente a relação do sujeito com os fenômenos objetivos". Entendemos haver uma perfeita coerência do pensamento do referido autor com o de Michel Pêcheux, na citação que aqui retomamos: "Todo discurso é o índice potencial de uma agitação nas filiações sócio-históricas de identificação, na medida em que ele constitui ao mesmo tempo um efeito dessas filiações e um trabalho (mais ou menos consciente, deliberado)". Encontramos também em Zoppi Fontana (1999, p.23) contribuições nesse sentido quando diz que "o processo de constituição do sujeito se dá pelas relações de identificação ideológica estabelecida com as posições de sujeito. [...] Nesse sentido, os lugares de enunciação se definem em relação ao funcionamento do Estado e de suas instituições".

As Formações ideológicas são definidas por Haroche (1971, p. 103) como "um conjunto complexo de atitudes e representações que nem são individuais nem universais, mas dizem respeito às posições de classes em conflito.” Representadas pela via de práticas sociais concretas, no interior das classes em conflito. Assim, cada Formação Ideológica estabelece um conjunto de valores, atitudes e representações historicamente definido em relação às classes em confronto - capital $\mathrm{x}$ trabalho -, dando lugar a discursos que põem à mostra posições em que os sujeitos se colocam. São, pois, expressão da estrutura ideológica de uma formação social que põe em jogo práticas associadas ás relações de classe e constituem matrizes comuns a um conjunto de discursos que expressam posições assumidas pelos sujeitos em diferentes práticas sociais concretas.

Voltemos às condições em que é produzido esse discurso de crítica às políticas compensatórias. As Condições de Produção do Discurso - categoria central da AD - englobam as condições materiais de produção do Discurso, ou seja, a situação mais imediata e o sujeito em suas relações mais amplas, resgatando pela memória sócio-histórica e ideológica, discursos outros. Vamos encontrar em Bakhtin/Volochinov (1981, p.122) o embrião

3 Disponível em http:/WWW.youtube.com/watch?v=khrWYPd3RQ 


\section{Conexão Letras}

desse conceito que depois é apropriado pela A.D. "A situação social mais imediata e o meio social mais amplo determinam completamente, e, por assim dizer, a partir do seu próprio interior, a estrutura da enunciação." Vejamos, pois a situação social imediata e as condições amplas em que Lula produz o seu discurso.

Ano de 2000, após mais uma disputa pela presidência da república entre Fernando Henrique Cardoso (candidato à reeleição) e Luis Inácio da Silva-derrotado pela terceira vez. Fernando Henrique, reeleito para o segundo mandato, já em 1999, implanta um Programa de Reforma e Proteção Social que engloba um conjunto de 22 programas selecionados nas áreas de saúde, educação, previdência e trabalho, destinados à prestação de serviços sociais básicos e voltados para grupos de baixa renda - Bolsa-Escola, Bolsa-Alimentação; Benefício Mensal - Portadores de Deficiência, Auxílio-gás, entre outros benefícios.

Lula, na condição de ex-presidente do Sindicato dos metalúrgicos do ABC e presidente de honra do Partido dos Trabalhadores, qualifica esses programas como paliativos, que não contribuem para que seus usuários adquiram autonomia financeira; ao contrário, funcionam como benesses, como favores que têm por objetivo manter os beneficiários na condição de eternos devedores dos seus benfeitores. É pois, a partir do lugar da classe dominada, do lugar do trabalhador explorado que ele enuncia, e, de sua percepção do momento político vigente, atribui sentidos aos programas assistencialistas: são peça de troca no momento da eleição; estratégia de despolitização do processo eleitoral; mecanismo de manutenção da política de dominação, secular no Brasil. Em termos de condições amplas do discurso, esse enunciado retoma a memória da formação social brasileira, capitalista, subdesenvolvida que, segundo Florencio et all (2009, p. 66), "se fez e ainda permanece com suas instituições impregnadas pelo abuso de poder, pelo favoritismo, nepotismos concretizados pelo uso de empregos públicos, usados como moeda de troca entre os políticos."

No caso específico dos programas de Proteção Social, a "moeda de troca" torna-se ainda mais cruel, pois consiste em trocar alimentos, artigos de subsistência por votos, uma vez que esses programas têm um destinatário específico: uma parte da sociedade que pelo alto grau de empobrecimento, é conduzida a pensar pelo estômago e não pela cabeça. Ser conduzido é ser incapaz de decidir sobre seu próprio rumo, ou mesmo não saber que rumo tomar. E o que produz esse fenômeno? "O alto grau de empobrecimento". É esse grau de empobrecimento extremo que desumaniza as pessoas, ao ponto de fazê-las "pensar com o estômago e não com a cabeça". Esse enunciado produz um efeito de sentido que nos leva a uma interpretação da metáfora do "estômago pensante", como uma denúncia do processo de desumanização a que é submetida (conduzida) a classe dominada, excluída de todos os bens socialmente produzidos. A essa classe é negado, inclusive o direito de escolher seus representantes, pois, afim de assegurar a alimentação para manter-se vivo, resta-lhe a opção de trocar seu voto por comida. Nessa perspectiva, a atividade do homem limita-se ao atendimento de uma necessidade instintiva, biológica - saciar a fome - como os animais, pois, segundo Leontiev, (2004, p..67),"a atividade dos animais é biológica, instintiva. Por outras palavras, a atividade animal não pode exercer-se senão em relação ao objeto de uma necessidade biológica." Continuando, o referido autor, (op. cit, p. 90), diz:

chamamos de pensamento, em seu sentido próprio, o processo de reflexo consciente da realidade, nas suas ligações e relações objetivas, incluindo os objetos inacessiveis á percepção imediata.[...] Razão por que é condição necessária do aparecimento do pensamento a distinção e a tomada de consciência das interações objetivas. Mas esta tomada de consciência é impossível nos limites da atividade instintiva dos animais. 
Por aí podemos deduzir que quem "é conduzido a pensar pelo estômago e não pela cabeça" não pensa, não decide nada. É necessário que alguém pense e decida em seu lugar É isso que acontece com a parte da sociedade que "é conduzida a pensar pelo estômago": Pelo seu "alto grau de empobrecimento não é capaz de perceber que a sua situação de miséria é causada pelo modelo injusto de sociedade capitalista, excludente que seus "benfeitores" lutam para manter." A esse respeito, já dizia Marx, nos manuscritos econômicos (2002, p.147), “Um ser só é independente quando é senhor de si mesmo, e só é senhor de si próprio quando a si mesmo deve a existência. $\mathrm{O}$ homem que vive pelo favor de outros se considera como um ser que depende. Vivo completamente de favor de outro, quando lhe devo não só a manutenção da minha vida, mas também a criação".

Mudam-se os lugares/mudam-se os sentidos

Passados não mais que dois anos, desencadeia-se uma nova disputa eleitoral pela Presidência da República. Nesse embate, destacam-se duas candidaturas - José Serra, candidato apoiado por Fernando Henrique Cardoso e, representando a oposição, o ex-sindicalista e ex-operário Luis Inácio Lula da Silva que adota como carro-chefe de sua campanha o combate à pobreza. Eleito com uma margem significativa de votos, assume a presidência da República, apresentando-se como representante da classe trabalhadora, de uma força política capaz de construir um novo Brasil "sem fome e sem miséria", e, uma das primeiras medidas de seu governo é a implantação do programa Fome Zero, ${ }^{4}$ vendo,nesse programa, a grande saída para a resolução do problema da fome e da miséria no Brasil. O documento intitulado Solidariedade, produzido pelo então Ministro extraordinário da Segurança Alimentar e Combate á Fome do governo Lula (2003) assim se refere ao programa Fome Zero: "é a primeira pedra dos alicerces para crescer com justiça social"5. Segundo Moreira et all(2005, p.138), “Os movimentos progressistas brasileiros viam essa campanha como uma possibilidade de profundas mudanças sociais [...] que, embora não sendo revolucionárias, significariam o fim do neoliberalismo. Por outro lado, os setores representantes do capital lançaram um olhar, [...] de forma positiva, na perspectiva de ampliação dos seus interesses".

Estaríamos, então, diante de um governo de consenso que representaria o fim do antagonismo existente acerca dos interesses do capital e do trabalho? Isso seria cabível num modo de produção capitalista cuja lógica se funda na exploração do trabalho do outro? Como isso seria possível sob a égide de uma sociedade capitalista cujos fins são expandir, cada vez mais seu processo de reprodução? PETRAS (2003, p.28) apresenta contribuições para a compreensão desse fenômeno. Diz ele:

Os meios financeiros brasileiros e estrangeiros, as instituições financeiras internacionais (o FMI, o Banco Mundial a Wall Street, a Cit de Londres e preeminentes líderes da direita, como o ministro Tony Blair e o presidente Bush) elogiaram Lula como "homem de Estado" e "líder carismático". Em outras palavras, os grandes capitais, os banqueiros e os líderes políticos da direita consideraram Lula um aliado na defesa de seus interesses contra a esquerda e os movimentos populares.

Por aí já podemos começar a desconfiar de que alguma coisa está errada. Como pode a classe dominante apoiar reformas que possam ameaçar o metabolismo do capital? Se as instituições financeiras, representantes do grande capital, não estão fazendo oposição a

4 Esse programa substitui o programa Comunidade Solidária do governo FHC

5 Disponível em: http:/PT.wikipedia.org/wiki/Bolsa_FamC3\%ADlia 


\section{Conexão Letras}

esses programas, se estão considerando Lula um seu aliado, é porque as políticas sociais implantadas, sob a aparência de um "Brasil Novo", nada mais são do que um conjunto de medidas resultantes de um "consenso passivo". Segundo Coutinho (2010, p. 12),

Esse tipo de consenso não se expressa pela auto-organização, pela participação ativa das massas, [...] mas simplesmente pela aceitação do existente como algo 'natural'. Mais precisamente, da transformação dos valores e ideias das classes dominantes em senso comum das grandes massa, inclusive das classes subalternas.

A partir do Programa Fome Zero, que vem em substituição do programa Comunidade Solidária do governo FHCF, surgem vários outros como: fortalecimento à agricultura familiar, programa primeiro emprego, microcrédito, entre outros. O Fome Zero, diz o já citado documento governamental "é um programa que, a partir de um conjunto de ações, tem como prioridade assegurar aos pobres o direito à vida, para que eles possam lutar pela própria sobrevivência" (grifo nosso).

Por questões administrativas de operacionalização o Programa Fome Zero é substituído pelo Programa Bolsa Família que unifica o Programa Fome Zero, mais quatro programas implantados no governo FHC - Bolsa Escola, Auxílio Gás, Bolsa Alimentação e o Cartão Alimentação. Vejamos o que diz o documento elaborado pelo Ministério de Desenvolvimento Social e Combate à Fome do governo Lula " "o Bolsa Família, além de representar uma evolução conceptual e operacional dos programas sociais está trazendo uma substancial economia de custos. [...] O governo trocou a dispersão pela unificação e passou a dar voz e vez a milhares de excluídos, para torná-los protagonistas de sua própria emancipação". (grifo nosso).

Em 2009, numa cerimônia em Belo Horizonte, o então presidente da república condena veementemente os que criticam o programa Bolsa Família.

Alguns dizem assim. O Bolsa Família é uma esmola; o Bolsa Familia é assistencialis-
mo; o Bolsa Família é demagogia e vai por aí. Tem gente tão imbecil, tão ignorante
que ainda fala: o Bolsa Família é para deixar as pessoas preguiçosas, porque quem
recebe o Bolsa Família não quer trabalhar. [...] O Bolsa Família é a porta de saída
da miséria e a porta de entrada num mundo melhor (Grifo nosso).

O que há de familiar nesses textos? Que leituras eles reclamam? Não nos causa estranheza que esse discurso seja produzido pelo mesmo enunciante que criticava as políticas compensatórias do seu antecessor? Ocorre que agora esse sujeito discursivo mudou de posição - da posição de sujeito sindicalista para a de presidente da república, representante do Estado e de suas instituições e, conforme Zoppi Fontana (1999, p. 23) "os lugares de enunciação se definem em relação ao funcionamento do Estado e de suas instituições", ou seja, o processo de constituição do sujeito se dá pelas relações de identificação/desidentificação ideológica das posições capital x trabalho em relação ao Estado. Assim, ao assumir a posição de um Estado cuja função é a defesa do capital é desse lugar que ele enuncia e, dessa posição, produz novos sentidos que apagam/desqualificam os discursos de crítica, inclusive o seu, produzindo um sentido antagônico para a mesma ação política - O Programa de combate à fome.

6 Disponível em:http://WWW.mds.gov.br/bolsafamilia. 
Vejamos.

\begin{tabular}{|l|l|l|}
\hline Lula 2002 & X & Lula 2009 \\
\hline Programas FHC & Programa Bolsa Família \\
- peça de troca eleitoral; & - dá voz e vez aos excluídos; \\
- estratégia de despolitização do processo & $\begin{array}{l}\text {-.torna os excluídos protagonistas de sua } \\
\text { eleitoral; }\end{array}$ & $\begin{array}{l}\text { própria emancipação; } \\
\text {-.mecanismo de manutenção da política de } \\
\text { dominação. }\end{array}$ \\
- porta de saída da miséria e porte de entrada \\
para um futuro melhor.
\end{tabular}

Tomemos alguns enunciados desse segundo momento "O governo trocou a dispersão pela unificação e passou a dar voz e vez a milhares de excluídos, para torná-los protagonistas de sua própria emancipação.”.(grifo nosso). O Bolsa Família é a porta de saída da miséria e a porta de entrada num mundo melhor (Grifo nosso). Vale lembrar que o Programa Bolsa Família consiste na ajuda financeira de $\mathrm{R} \$ 60,00$, às famílias pobres (definidas como aquelas que possuem renda per capta de 70 até 140 reais) e extremamente pobres (com renda per capta menor que 70 reais). A contrapartida é que as famílias beneficiárias mantenham seus filhos e/ou dependentes frequentando a escola e vacinados. Ora, uma família de 4 pessoas com a renda per capta de 70 reais, recebe por mês 280 reais + 240 do Bolsa Família, 520 reais. Na realidade econômica atual, essa quantia é suficiente apenas para que adquiram o básico para sua alimentação. Essas pessoas não estariam também "sendo conduzidas a pensar pelo estômago e não pela cabeça? Como poderiam ser "protagonistas de sua própria emancipação". O que seria "ser protagonista de sua própria emancipação"? Seria poder decidir os rumos de sua vida, tendo consciência do que produz, para que e para quem produz. É ter consciência de que o produto de seu trabalho gera riqueza, e, se essa riqueza não melhora sua condição de vida é porque ela é apropriada por outros. É não se resignar com as condições de existência impostas pela sociedade que lhe permitem apenas satisfazer, de modo ainda precário, suas necessidades essenciais e primárias: comer, beber e reproduzir-se. É isso que uma renda Segundo Marx e Engels (2004, p. 10), "A emancipação dos indivíduos, sua libertação das condições opressoras só poderia se dá quando alcançasse todos os níveis, e, entre eles, o da consciência. Somente a educação, a ciência e a extensão do conhecimento, o desenvolvimento da razão, pode conseguir tal objetivo."

Nesse mesmo sentido, Tonet (2005, p. 222) afirma que propiciar a emancipação humana é garantir ao indivíduo "a apropriação de conhecimentos, habilidades, valores, etc, que se constituem em patrimônio acumulado ao longo da história da humanidade." Nesse sentido, contribui para que o indivíduo se construa como membro do gênero humano.

Um outro sentido atribuído ao programa Bolsa Família é que ela "é a porta de saída da miséria e a porta de entrada num mundo melhor". O que significa um mundo melhor para quem ultrapassa os umbrais da miséria? A nosso ver, não seria um mundo melhor, pois o mundo da miséria não bom; seria um mundo menos ruim, menos miserável, apenas.

Entretanto, muitos defensores do Bolsa Família argumentam: mas agindo assim o governo não está de fato, melhorando as condições de vida dessa população? ? Os usuários desse programa também o consideram uma benesse do governo, emitindo sobre ele algumas avaliações do tipo: "melhor po.uco do que nada"; "o pouco com Deus é muito" 
Consideramos pertinente a contribuição de Courtine (b 2006, p. 21) que, ao falar sobre "A arte da mentira política" diz que para levar a bom termo um projeto pçlítico, certas condições são imprescindíveis. "É necessário dispor de uma massa de crédulos prontos a repetir, expandir, disseminar por toda parte as falsas notícias forjadas. A reserva de ingênuos é indispensável, pois, 'não há homem que recite e espalhe uma mentira com tanta graça como aquele que acredita nela". Consideramos pertinente também, trazer aqui, uma citação contida em um artigo de Michel Pêcheux intitulado: Foi "propaganda" mesmo que você disse? Nesse artigo, falando sobre propaganda política, Pêcheux refere-se a Tchakotin, formulador da bio-psicologia da propaganda, autor de Violação das multidões pela propaganda política, publicado em 1939. Sobre o referido teórico diz Pêcheux (2011, p. 37), "numerosos são hoje aqueles que de diversos horizontes tomariam essas terríveis palavras de Tchakotin (1939, apud, Pêcheux, 2011, p. 38).

O grande perigo que a humanidade corre é determinado por três fatos: o primeiro deles é que há homens que perceberam a possibilidade, no estado em que se encontra a maior parte de seus contemporâneos, de fazer deles marionetes, de fazê-los servir a seus fins. [...] O segundo fato é precisamente que essas possibilidades existem e que a proporção dos seres humanos que sucumbem a elas é espantosa - dez contra um. O terceiro fato consiste em em que a violação psiquica coletiva pelos usurpadores se faz sem que nada se oponha a ela, sem que estes que deviam velar para impedi-la percebam o perigo.

\section{Considerações finais}

Como diz Orlandi (1995, p,30) “o sentido não está (alocado) em lugar nenhum, mas se produz nas relações: dos sujeitos, dos sentidos, e isso só é possível, já que sujeito e sentido se constituem mutuamente, pela sua inscrição no jogo das múltiplas formações discursivas. Hoje com as estratégias do Estado Neoliberal, criado para recompor a crise que se instalou no Sistema Capitalista na década de 70 e 90, estamos assistindo a um projeto que se alastra construindo sentidos que se legitimam a favor do bloco dominante e, para manter seu projeto hegemônico é necessário impor uma intensa dinâmica de mudança material e, ao mesmo tempo, uma não menos intensa dinâmica de reconstrução discursivo-ideológica da sociedade,

Para atingir seus objetivos, e, ao mesmo tempo, mascarar/ocultar seu comprometimento com determinados grupos, lança mão de vários mecanismos discursivos que produzem "excelentes" resultados ideológicos, por sua capacidade de anular a reflexão crítica. Travase, então, no espaço político uma luta não só pela tomada e manutenção do poder, mas também pela tomada e manutenção da palavra. Por isso, a conquista da mídia tem sido uma prioridade da política, pois não basta apenas ocupar os canais de comunicação, mas também conquistar a legitimação midiática e fechar o acesso aos adversários, impondo seus consensos e valores. A nosso ver, é isso que constatamos nas posições de sujeito assumidas pelo ex-presidente, Luis Inácio Lula da Silva nas materialidades que analisamos.

Para entender os processos de sustentação desse discurso político, é necessário recorrer aos pressupostos teórico-metodológicos da Análise do Discurso. Essa teoria nos fornece subsídios que nos permitem desvelar os discursos, visto que não se limita, apenas, a interpretar fatos na sua aparência fenomênica, mas busca entender esses fatos pela via da conjuntura histórico-ideológica que possibilita o seu surgimento. A AD descreve e interpreta como os sentidos se constituem e se fixam na sociedade, sempre na articulação indissociável entre a língua e a história. 
Referências

BAKHTIN, Mikhail, Marxismo e filosofia da linguagem. São Paulo: Hucitec, 1981. COUTINHO, Carlos Nelson - "Hegemonia da pequena política" in: OLIVEIRA, Francisco de et all - Hegemonia ás avessas. São Paulo: Boitempo, 2010.

FLORENCIO, Ana Maria Gama et all-Análise do discurso: procedimentos \& prática. Maceió: EDUFAL, 2009

GREGOLIN, Maria do Rosário - "Sentido, sujeito e memória: com que sonha nossa vã autoria?" in: GREGOLIN, Maria do Rosátio et all (ORG.) Análise do discurso: as metarialidades do sentido. São Carlos: Clara Luz, 2003.

LEONTIEV, Alexis, Desenvolvimento do psiquismo. São Paulo: Centauro, 2004.

MAGALHÃES, Belmira Rita, et all - História, consciente e inconsciente:o sujeito na análise do discurso in: Revista LEITURA, № 40. Maceió: EDUFAL, 2007.

MARX, Karl - Manuscritos econômicos filosóficos. São Paulo: Martin Claret, 2002.

MOREIRA, Luciano Accyoli Lemos - "Fome zero: uma ação política a um mal social?

In: CAVALCANTE, Maria do Socorro Aguiar de Oliveira (org.) As malhas de discursos (re)veladores. Maceió: EDUFAL, 2005.

ORLANDI, Eni - As formas do silêncio no movimento dos sentidos. São Paulo:

UNICAMP, 1995.

-Uma tautologia ou um embuste semântico discursivo? Ainda a propaganda de

Estado: país rico é pais sem pobreza in: DIAS, Verli e PETRI, Cristiane (orgs) Análise do discurso em perspectiva Santa Maria: Ed. Ufsm, 2013.

PÊCHEUX, Michel, Semântica e discurso. Campinas: UNICAMP, 1988

- "Foi "propaganda" mesmo que você disse:" in: ORLANDI, Eni, - Análise de

discurso Michel Pêcheux. Campinas: Pontes,2011.

PETRAS, James - "Para onde vai o Brasil?" in:Marxismo vivo: revista internacional, n.

7. São Paulo: Instituto José Luis e Rosa Sunderman, 2003.

TONET, Ivo, - Educação, cidadania e emancipação humana. Rio Grande do Sul: Unijuí, 2005.

ZOPPI FONTANA, Mónica - "Lugares de enunciação e discurso" in: Revista

LEITURA, N. 23. Maceió: EDUFAL, 1999.

VÍDEO - Lula contra Lula Disponível em:http://WWW.mds.gov.br/bolsafamilia 